\title{
The influence of maximum safe resection of glioblastoma on survival in 1229 patients: Can we do better than gross-total resection?
}

\author{
*Yan Michael Li, MD, PhD, ${ }^{1,2}$ Dima Suki, PhD, ${ }^{1}$ Kenneth Hess, PhD, ${ }^{3}$ and Raymond Sawaya, MD1 \\ Departments of ${ }^{1}$ Neurosurgery and ${ }^{3}$ Biostatistics, The University of Texas MD Anderson Cancer Center, Houston, Texas; \\ and 'Department of Neurosurgery and Oncology, University of Rochester Medical Center School of Medicine and Dentistry, \\ Rochester, New York
}

\begin{abstract}
OBJECTIVE Glioblastoma multiforme (GBM) is the most common and deadliest primary brain tumor. The value of extent of resection (EOR) in improving survival in patients with GBM has been repeatedly confirmed, with more extensive resections providing added advantages. The authors reviewed the survival of patients with significant EORs and assessed the relative benefit/risk of resecting $100 \%$ of the MRI region showing contrast-enhancement with or without additional resection of the surrounding FLAIR abnormality region, and they assessed the relative benefit/risk of performing this additional resection.
\end{abstract}

METHODS The study cohort included 1229 patients with histologically verified GBM in whom $\geq 78 \%$ resection was achieved at The University of Texas MD Anderson Cancer Center between June 1993 and December 2012. Patients with $>1$ tumor and those 80 years old or older were excluded. The survival of patients having $100 \%$ removal of the contrastenhancing tumor, with or without additional resection of the surrounding FLAIR abnormality region, was compared with that of patients undergoing $78 \%$ to $<100 \%$ EOR of the enhancing mass. Within the first subgroup, the survival durations of patients with and without resection of the surrounding FLAIR abnormality were subsequently compared. The data on patients and their tumor characteristics were collected prospectively. The incidence of 30-day postoperative complications (overall and neurological) was noted.

RESULTS Complete resection of the T1 contrast-enhancing tumor volume was achieved in 876 patients (71\%). The median survival time for these patients (15.2 months) was significantly longer than that for patients undergoing less than complete resection ( 9.8 months; $p<0.001$ ). This survival advantage was achieved without an increase in the risk of overall or neurological postoperative deficits and after correcting for established prognostic factors including age, Karnofsky Performance Scale score, preoperative contrast-enhancing tumor volume, presence of cyst, and prior treatment status (HR 1.53, 95\% Cl 1.33-1.77, $\mathrm{p}<0.001)$. The effect remained essentially unchanged when data from previously treated and previously untreated groups of patients were analyzed separately. Additional analyses showed that the resection of $\geq 53.21 \%$ of the surrounding FLAIR abnormality beyond the $100 \%$ contrast-enhancing resection was associated with a significant prolongation of survival compared with that following less extensive resections (median survival times 20.7 and 15.5 months, respectively; $p<0.001$ ). In the multivariate analysis, the previously treated group with $<53.21 \%$ resection had significantly shorter survival than the 3 other groups (that is, previously treated patients who underwent FLAIR resection $\geq 53.21 \%$, previously untreated patients who underwent FLAIR resection $<53.21 \%$, and previously untreated patients who underwent FLAIR resection $\geq 53.21 \%$ ); the previously untreated group with $\geq 53.21 \%$ resection had the longest survival.

CONCLUSIONS What is believed to be the largest single-center series of GBM patients with extensive tumor resections, this study supports the established association between EOR and survival and presents additional data that pushing the boundary of a conventional $100 \%$ resection by the additional removal of a significant portion of the FLAIR abnormality region, when safely feasible, may result in the prolongation of survival without significant increases in overall or neurological postoperative morbidity. Additional supportive evidence is warranted.

http://thejns.org/doi/abs/10.3171/2015.5.JNS142087

KEY WORDS glioblastoma multiforme; prognosis; extent of resection; survival; oncology

ABBREVIATIONS EOR = extent of resection; GBM = glioblastoma multiforme; KPS = Karnofsky Performance Scale; MD Anderson = The University of Texas MD Anderson Cancer Center; UCSF = University of California, San Francisco.

SUBMITTED September 5, 2014. ACCEPTED May 7, 2015.

INCLUDE WHEN CITING Published online October 23, 2015; DOI: 10.3171/2015.5.JNS142087.

* Drs. Li and Suki contributed equally to this work. 
$\mathrm{G}$ LIOBLASTOMA multiforme (GBM) is the most common and deadliest primary brain tumor. ${ }^{14}$ The incidence of the disease is 5 to 10 cases per 100,000 persons per year, and more than 14,000 new cases of GBM are diagnosed in the United States each year. ${ }^{7} \mathrm{Al}-$ though new treatment paradigms have had a significant impact on the outcomes of many other cancer types, the treatment of patients with GBM remains a challenge. $\mathrm{Pa}$ tients survive for an average of 14 months from diagnosis despite maximal treatment with surgery, chemotherapy, and radiation therapy, ${ }^{23}$ and the duration of survival has not changed significantly in decades.

The role of surgery in the management of GBM has been extensively investigated. Initial studies traditionally classified extent of resection (EOR) within the arbitrary categories of gross-total, subtotal, and partial resection. Our previous study on 416 patients with newly diagnosed and recurrent GBM shifted that paradigm of the 3 arbitrary categories into the concept of maximal, safely achievable volumetric resection, demonstrating an incremental increase in the duration of survival with each unit increase in the EOR, starting from $89 \%,{ }^{15}$ with the strongest effect of resection on survival being achieved at the $98 \%$ threshold. Years later, these results were supported by investigators from the University of California, San Francisco (UCSF) in a retrospective review of 500 consecutive patients with newly diagnosed GBM, with minor differences in the EOR threshold, probably reflecting the distribution of EOR between the 2 study samples. ${ }^{20}$ The UCSF data showed a significant survival advantage starting at $78 \%$ EOR instead of the $89 \%$ reported in our series, and an EOR $\geq 95 \%$ had the greatest impact on overall survival instead of the $\geq 98 \%$ from our series. The median survival time among the 316 UCSF patients in the $\geq 95 \%$ EOR category was 14.5 months..$^{20}$ Our group recently revisited data from 721 adult patients with GBM from 1993 to 2012 and provided further evidence supporting a maximum safe resection approach for GBM. ${ }^{19}$

Glioblastoma multiforme is regularly described as an invasive tumor. ${ }^{26}$ The motility of GBM cells has been demonstrated in vitro in cell cultures, ${ }^{2,12}$ in postmortem studies, ${ }^{3,4,27}$ and in stereotactic biopsy specimens, ${ }^{10,13}$ as well as in other studies..$^{5,17,18,24}$ The area outside the contrastenhancement region on a T1-weighted MR image is usually infiltrated by tumor cells. ${ }^{26}$ Fluid-attenuated inversion recovery (FLAIR) images are thought to represent these invasive cells, ${ }^{8,13}$ as well as cerebral edema, demyelination, and/or surgery-related injury..$^{9,28}$ In a general review of GBM, Wilson points to the inadequacy of the current treatment paradigms for the patient presenting with GBM and links the probability of recurrence at any site to the number of cells left behind at or around the initial GBM site, ${ }^{26}$ supporting his theory by the fact that $80 \%-90 \%$ of patients who succumb to GBM die of local tumor recurrence, ${ }^{4,6,11,25}$ unlike those with other malignant tumors who die of metastasis.

If increasing the resection of the contrast-enhancing portion of a GBM leads to increased survival, based on the above 2 studies and other supportive literature, does $100 \%$ resection of the contrast-enhancing tumor confer a significant survival advantage relative to that obtained following the less expansive, though still extensive, resection? And would the additional removal of infiltrating tumor cells, as identified by FLAIR abnormality on T2-weighted MR images, have a significant impact? To answer these 2 questions, we identified patients undergoing an EOR $\geq 78 \%$ at our institution. We first compared the survival of patients with $78 \%$ to $<100 \%$ EOR with that of patients undergoing $100 \%$ EOR of the enhancing mass (with or without additional resection of the FLAIR abnormality). An EOR of $100 \%$ of the enhancing lesion is hereafter referred to as complete resection. The $78 \%$ cutoff was chosen because it was the lower of the 2 thresholds most significantly associated with survival in the prior MD Anderson and UCSF studies. ${ }^{20}$ In a secondary analysis, we reviewed the effect of the additional resection of the FLAIR abnormality region on survival within the group of patients undergoing complete resection of the enhancing lesion. The incidence of postoperative complications-overall and neurological-was also reviewed.

\section{Methods}

\section{Patients and Treatment Characteristics}

The study was conducted under the auspices of an institutional review board-approved protocol. In a search of the Brain and Spine Center Database at the University of Texas MD Anderson Cancer Center (MD Anderson), we identified all consecutive patients with GBM who had undergone tumor resection between June 1993 and December 2012. All cases had a diagnosis of GBM according to the Ringertz classification, Grade IV astrocytoma according to the WHO classification, and Grade 4 astrocytoma according to the St. Anne-Mayo classification. ${ }^{15} \mathrm{We}$ excluded patients having more than $1 \mathrm{GBM}$, those aged 80 years or more at the time of surgery, and those with < $78 \%$ contrast-enhancing tumor resection. The final sample consisted of 1229 patients with GBM.

Demographic, clinical, and imaging data were obtained from the prospectively collected Brain and Spine Center Database. Each patient's age, sex, and Karnofsky Performance Scale (KPS) score at the time of surgery was obtained. Previous neurosurgeries were recorded, including those undergone at another center, including cytoreductive surgery or a biopsy procedure with or without adjuvant chemotherapy or radiation therapy, which indicated that the patient had residual or recurrent tumor at the time of presentation at our institution. Such patients are referred to hereafter as the previously treated group. The MD Anderson Tumor Registry was used to identify each patient's vital status at the time of data analysis. The tumor registry staff ascertain the vital status of all patients seen at our institution through sources such as the National Death Index and from letters or phone calls to patients and their families.

\section{Imaging Studies}

Preoperative and postoperative MR images (typically obtained within 48 hours after surgery) are routinely reviewed at our institution in a prospective fashion. Several tumor imaging characteristics are identified and entered into the Brain and Spine Center Database. Tumor location in regard to proximity to eloquent brain is characterized by functional grade, as described by Sawaya et al. ${ }^{21}$ The 
presence of mass effect, surrounding edema, and contrastenhancement of the tumor mass are also assessed. Preoperative and postoperative tumor volumes are quantified. Tumor contrast-enhanced volume is defined as the area of increased signal intensity on contrast-enhancing T1-weighted MR images. The FLAIR abnormality volume is defined as the area of FLAIR hyperintensity signal seen on T2-weighted MR images beyond the contrast-enhanced T1-weighted images. The Vitrea software version 2 is currently used for these studies (the MedVision 1.41 computer software program from Technologies Inc. was used for older cases). This software allows calculation of the tumor area as outlined on selected axial or coronal images and then the estimation of tumor volume based on the known thickness of the slice.

\section{Statistical Analyses}

The primary objective of this study was to establish whether complete resection of the contrast-enhancing lesion $(100 \%)$, as determined on the basis of objectively quantified preoperative and postoperative volume estimates, has prognostic value with regard to patient survival time after surgery, compared with resection $<100 \%$. The secondary objectives were to examine whether additional resection of the region corresponding to the FLAIR abnormality beyond the contrast-enhancing area has a significant effect on survival time overall or within defined patient subgroups and to assess the incidence of overall and neurological complications associated with different EOR scenarios.

To achieve these objectives, frequencies and descriptive statistics of the variables under study were obtained. A recursive partitioning analysis was performed to identify a cutoff for continuous variables, if one existed. The cumulative survival duration measured from the time of surgery at our institution was computed using the Kaplan-Meier method. Survival curves for the various subgroups were compared using the log-rank test. The Cox proportional hazards model was used to identify factors associated with survival at the univariate and multivariate levels. Crude

TABLE 1. Characteristics of 1229 patients with GBM*

\begin{tabular}{|c|c|c|c|c|}
\hline Characteristic & Total No. & $\begin{array}{l}100 \% \text { Resection of } \mathrm{T} 1 \\
\text { Contrast-Enhancing Vol }\end{array}$ & $\begin{array}{c}78 \% \text { to }<100 \% \text { Resection } \\
\text { of T1 Contrast-Enhancing } \\
\text { Vol }\end{array}$ & p Value \\
\hline No. of patients & 1229 & 876 & 353 & \\
\hline Median age at surgery in yrs (min, max) & $55.7(4.6,80.0)$ & $55.5(4.6,80.0)$ & $56.7(6.0,79.5)$ & 0.2 \\
\hline \multicolumn{5}{|l|}{$\operatorname{Sex}(\%)$} \\
\hline Male & $758(62)$ & $539(62)$ & $219(62)$ & \\
\hline Female & $471(38)$ & $337(38)$ & $134(38)$ & 0.87 \\
\hline Median preop KPS score (min, max) & $90(10,100)$ & $90(20,100)$ & $80(10,100)$ & $<0.001$ \\
\hline \multicolumn{5}{|l|}{ Preop KPS score (\%) } \\
\hline$\geq 70$ & $1134(92)$ & $819(93)$ & $315(89)$ & \\
\hline$<70$ & $95(8)$ & $57(7)$ & $38(11)$ & 0.01 \\
\hline \multicolumn{5}{|l|}{ Tumor functional grade $(\%) \dagger$} \\
\hline 1 & $166(14)$ & $151(17)$ & $15(4)$ & \\
\hline 2 & $589(48)$ & $409(47)$ & $180(51)$ & \\
\hline 3 & $469(38)$ & $313(36)$ & $156(44)$ & $<0.001$ \\
\hline \multicolumn{5}{|l|}{ Symptoms before surgery (\%) } \\
\hline No & $105(9)$ & $85(10)$ & $20(6)$ & \\
\hline Yes & $1124(91)$ & $791(90)$ & $333(94)$ & 0.02 \\
\hline \multicolumn{5}{|l|}{ Previously treated (\%) } \\
\hline No & $752(61)$ & $539(62)$ & $213(60)$ & \\
\hline Yes & $477(39)$ & $337(38)$ & $140(40)$ & 0.70 \\
\hline \multicolumn{5}{|l|}{ Necrosis on imaging $(\%) \ddagger$} \\
\hline No & $265(22)$ & $225(26)$ & $40(11)$ & \\
\hline Yes & $961(78)$ & $648(74)$ & $313(89)$ & $<0.001$ \\
\hline \multicolumn{5}{|l|}{ Cyst on imaging (\%)‡ } \\
\hline No & $1108(90)$ & $780(89)$ & $328(93)$ & \\
\hline Yes & $118(10)$ & $93(11)$ & $25(7)$ & 0.06 \\
\hline $\begin{array}{l}\text { Median preop T1 contrast-enhancing vol } \\
\text { in } \mathrm{cm}^{3}(\min , \max ) \S\end{array}$ & $\begin{array}{c}31.0(0.3 \\
186.3)\end{array}$ & $25.9(0.3,175.1)$ & $46.3(3.9,186.3)$ & $<0.001$ \\
\hline
\end{tabular}


TABLE 2. Outcomes in 1229 patients with GBM treated with resection of the T1 contrast-enhancing volume*

\begin{tabular}{|c|c|c|c|c|}
\hline Variable & Total No. & $100 \%$ Resection & $78 \%$ to $<100 \%$ Resection & p Value \\
\hline No. of patients & 1229 & 876 & 353 & \\
\hline \multicolumn{5}{|l|}{ EOR of T1 contrast-enhancing vol (\%) } \\
\hline $100 \%$ & $876(71)$ & & & \\
\hline $78 \%$ to $<100 \%$ & $353(29)$ & & & \\
\hline \multicolumn{5}{|l|}{ Vital status at last follow-up (\%) } \\
\hline Alive & $194(16)$ & $154(18)$ & $40(11)$ & \\
\hline Dead & $1035(84)$ & $722(82)$ & $313(89)$ & 0.007 \\
\hline Median overall survival in mos $(95 \% \mathrm{Cl})$ & $13.4(12.6,14.1)$ & $15.2(14.1,16.3)$ & $9.8(8.8,10.8)$ & $<0.001$ \\
\hline \multicolumn{5}{|l|}{ 30-day postop complications (\%) } \\
\hline No & $950(77)$ & $693(79)$ & $257(73)$ & \\
\hline Yes & $279(23)$ & $183(21)$ & $96(27)$ & 0.02 \\
\hline \multicolumn{5}{|l|}{ 30-day postop neurological complications (\%) } \\
\hline No & $1002(82)$ & $728(83)$ & $274(78)$ & \\
\hline Yes & $227(18)$ & $148(17)$ & $79(22)$ & 0.02 \\
\hline Motor deficit & $115(9)$ & $75(9)$ & $40(11)$ & 0.13 \\
\hline Speech impairment & $77(6)$ & $50(6)$ & $27(8)$ & 0.20 \\
\hline Visual impairment & $33(3)$ & $21(2)$ & $12(3)$ & 0.32 \\
\hline Seizure & $30(2)$ & $17(2)$ & $13(4)$ & 0.07 \\
\hline Hemorrhage & $17(1)$ & $12(1)$ & $5(1)$ & 1.00 \\
\hline Intracranial hemorrhage & $14(1)$ & $10(1)$ & $4(1)$ & 1.00 \\
\hline Hydrocephalus & $12(<1)$ & $7(<1)$ & $5(1)$ & 0.34 \\
\hline Cognitive/memory/mental status problems & $12(<1)$ & $8(<1)$ & $4(1)$ & 0.06 \\
\hline Sensory deficit & $7(<1)$ & $4(<1)$ & $3(<1)$ & 0.42 \\
\hline Headache & $8(<1)$ & $5(<1)$ & $3(<1)$ & 0.70 \\
\hline Cranial nerve deficit & $6(<1)$ & $5(<1)$ & $1(<1)$ & 0.68 \\
\hline Other† & $36(3)$ & $24(3)$ & $12(3)$ & 0.54 \\
\hline
\end{tabular}

and adjusted hazard ratios and their $95 \%$ confidence intervals were calculated. All p values ranging from 0.0001 to 0.1 for categorized continuous variables were adjusted to achieve an approximate false-positive rate of $10 \%$, based on the paper by Altman et al..$^{1}$ All tests were 2-tailed. A p value $\leq 0.05$ was considered significant. Statistical analyses were performed using the Statistical Package for the Social Sciences 21.0 (SPSS Inc.). The recursive partitioning analysis was performed using the $\mathrm{R}$ software (version 3.1.0).

\section{Results \\ Patient and Tumor Characteristics}

Table 1 summarizes the demographic, clinical, and tumor characteristics of the study patients. The median age was 55.7 years (range 4.6-80.0 years). Most patients were male $(62 \%)$. The median KPS score was 90 (range 10-100), and $92 \%$ of patients had a score of at least 70 . Most patients $(91 \%)$ had symptoms before surgery. Previously untreated patients accounted for $61 \%$ of the group. Based on preoperative MR images, $14 \%$ of tumors were presumably located in noneloquent brain (Grade 1), $48 \%$ were located in neareloquent brain (Grade 2), and 38\% were within eloquent brain area (Grade 3). ${ }^{21}$ Necrosis was documented in $78 \%$ of tumors; a cystic component was found in $10 \%$ of tumors. The median preoperative contrast-enhancing tumor volume was $31.0 \mathrm{~cm}^{3}$ (range $0.3-186.3 \mathrm{~cm}^{3}$ ).

Complete resection (100\%) of the T1 contrast-enhancing part of the tumor was achieved in 876 patients (71\%). Less than complete resection $(78 \%$ to $<100 \%)$ was achieved in 353 patients $(29 \%)$. These 2 patient groups had different distributions with respect to preoperative KPS scores, tumor functional grade, preoperative contrast-enhancing tumor volume, and presence of necrosis, as well as preoperative symptoms (Table 1). They were comparable in terms of patient age, sex, presence of cysts on imaging, and prior treatment status. The median duration of followup among the 194 patients remaining alive at the end of the study was 19.9 months (range 0.1-190.1 months).

\section{Analysis of Overall Survival}

The Kaplan-Meier estimate of median postoperative survival time for the 1229 study patients was 13.4 months (95\% CI 12.6-14.1 months; Table 2). Patients with complete resection (100\% of contrast-enhancing region) had a median survival time of 15.2 months (95\% CI 14.1-16.3 


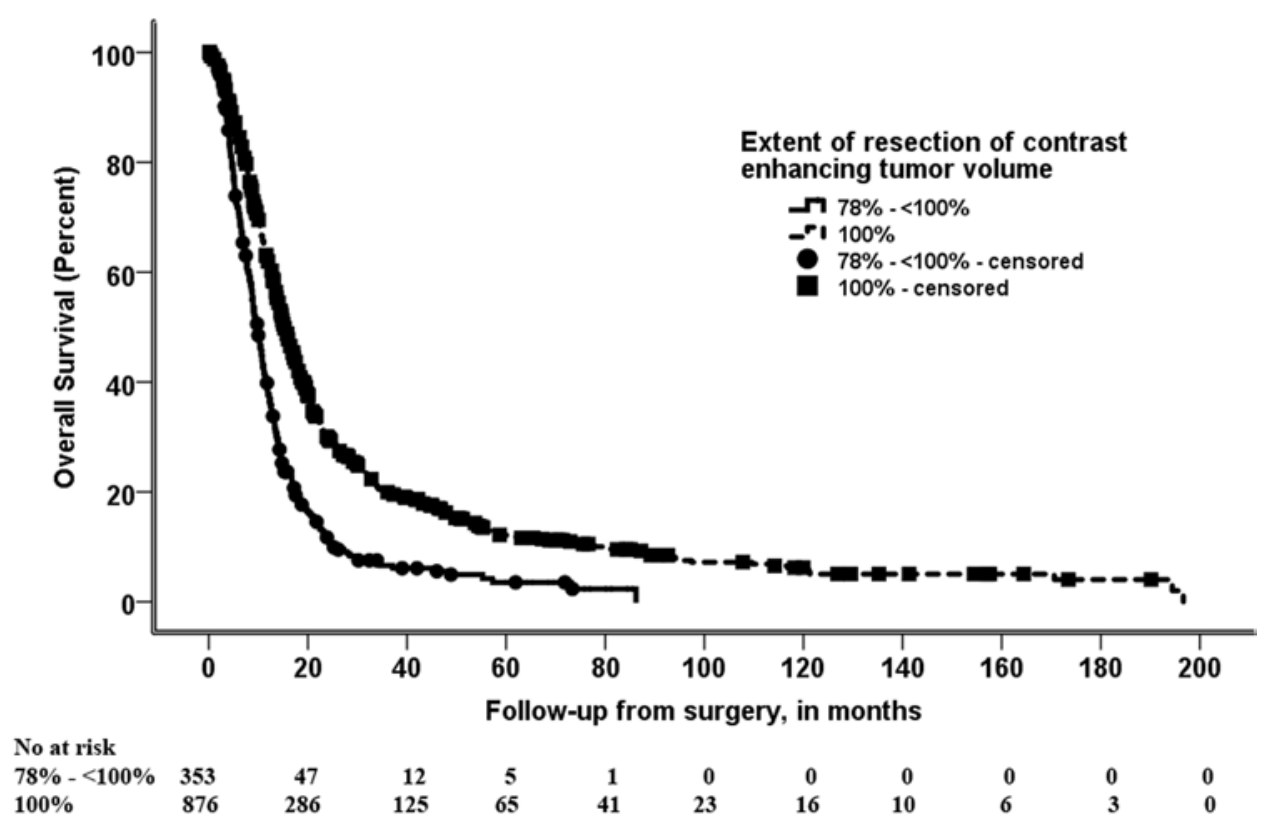

FIG. 1. Kaplan-Meier plot of overall survival in a series of 1229 patients with GBM after different degrees of resection of the contrast-enhancing tumor volume. Compare the complete resection group (dashed line, 100\%; black squares, 100\%-censored) with the group that underwent less than complete resection (solid line, $78 \%$ to $<100 \%$; black circles, $78 \%$ to $<100 \%$-censored).

months), a duration significantly longer than the median survival of patients with less than complete resection $(9.8$ months, 95\% CI 8.8-10.8 months; $\mathrm{p}<0.001$; Fig. 1). Patients without complete resection had a univariate HR of 1.87 (95\% CI 1.63-2.14, $\mathrm{p}<0.001)$ compared with patients undergoing complete resection (Table 3). This observed difference in survival between these 2 groups remained significant when other prognostic factors were adjusted for in a multivariate Cox model analysis: less than complete resection had an adjusted HR of 1.53 (95\% CI 1.33-1.77, $\mathrm{p}<0.001)$. Additional factors found to have a significant negative independent effect on survival duration in the multivariate analysis included an older age at surgery (HR $1.03,95 \%$ CI $1.02-1.03$; p < 0.001), a previously treated status (HR 1.67, 95\% CI 1.46-1.90; $\mathrm{p}<0.001$ ), a preoperative KPS score less than 70 (HR 1.30, 95\% CI 1.04-1.64; $\mathrm{p}=0.02)$, and a larger preoperative contrast-enhancing tumor volume (HR 1.005, 95\% CI 1.002-1.007; p < 0.001). The presence of a cyst had a positive impact on the duration of survival (HR 0.63, 95\% CI 0.50-0.79; p < 0.001).

The 2 resection groups had significant differences in important characteristics, which could have impacted their effect on overall survival. Table 4 shows the effect of EOR within various categories of these characteristics (variables). The hazard ratio remained basically unaltered in terms of direction, and the $\mathrm{p}$ values remained significant in all categories except for an asymptomatic presentation. There were too few patients without symptoms in this series.

We performed a close and separate examination of previously untreated and previously treated patients and found similar negative prognostic effects for a less-thancomplete resection in both groups (adjusted HR 1.69, 95\% CI 1.41-2.04, p < 0.001, and adjusted HR 1.33, 95\% CI $1.06-1.67, \mathrm{p}=0.02$, respectively; data not shown).
To address one of the secondary objectives of the study - that is, whether additional resection of the FLAIR abnormality region beyond the enhancing area would have a significant effect on survival time overall or within defined patient subgroups-patients who underwent complete resection of the contrast-enhancing tumor volume were further examined. Of the 876 patients who had undergone complete resection, 643 underwent further resection of the T2 FLAIR abnormality region and had FLAIR data. The distribution of the EOR of the FLAIR abnormality area is presented in Fig. 2. Approximately $18 \%$ of the patients had a negative EOR, reflecting the development of postoperative edema. In the 643-patient subgroup, a FLAIR abnormality resection $\geq 53.21 \%$, compared with one $<53.21 \%$, was significantly associated with improved survival in the univariate analysis (median 20.7 months, compared with 15.5 months; crude HR 0.68 , 95\% CI 0.550.84, $\mathrm{p}<0.001$; Tables 5 and 6). In the multivariate analysis, the previously treated group with a FLAIR resection $<53.21 \%$ fared significantly worse than all others (that is, previously treated patients who underwent FLAIR resection $\geq 53.21 \%$, previously untreated patients who underwent FLAIR resection $<53.21 \%$, and previously untreated patients who underwent FLAIR resection $\geq 53.21 \%$ ). The untreated group with at least $53.21 \%$ resection had the longest survival. Prior treatment in the 643-patient subgroup included prior resection in $100 \%$ of the patients, prior radiation in $189(79 \%)$, and prior chemotherapy in 177 (74\%; $61 \%$ of which received temozolomide; $72 \%$, both radiation and chemotherapy; and $60 \%$, both radiation and temozolomide). The median preoperative FLAIR abnormality volume was $57.3 \mathrm{~cm}^{3}$ in patients who had received prior radiation and/or chemo, compared with $33.3 \mathrm{~cm}^{3}$ in those who had not $(\mathrm{p}=0.17)$. The median extent of FLAIR abnormality resection was $22 \%$ in patients who received 
TABLE 3. Overall survival analysis in 1229 patients with GBM

\begin{tabular}{|c|c|c|c|c|c|c|c|c|c|c|}
\hline \multirow[b]{2}{*}{ Variable } & \multicolumn{4}{|c|}{ Kaplan-Meier Analysis } & \multicolumn{3}{|c|}{ Univariate Analysis } & \multicolumn{3}{|c|}{ Multivariate Analysis } \\
\hline & $\begin{array}{l}\text { Total No. } \\
\text { of Patients }\end{array}$ & Events & $\begin{array}{c}\text { Median } \\
\text { Survival } \\
\text { (mos) }\end{array}$ & $95 \% \mathrm{Cl}$ & $\mathrm{HR}$ & $95 \% \mathrm{Cl}$ & $\begin{array}{c}p \\
\text { value }\end{array}$ & $\mathrm{HR}$ & $95 \% \mathrm{Cl}$ & $\begin{array}{c}\mathrm{p} \\
\text { Value }\end{array}$ \\
\hline Age at surgery & - & - & - & - & 1.03 & $1.02-1.03$ & $<0.001$ & 1.03 & $1.02-1.03$ & $<0.001$ \\
\hline \multicolumn{11}{|l|}{ Age at surgery in yrs } \\
\hline$\leq 51.7$ & 456 & 349 & 17.3 & $15.3-19.4$ & 1.00 & & & & & \\
\hline$>51.7$ & 773 & 686 & 11.9 & $11.1-12.7$ & 1.74 & $1.53-1.99$ & $<0.001$ & & & \\
\hline \multicolumn{11}{|l|}{$\operatorname{Sex}(\%)$} \\
\hline Male & 758 & 639 & 13.0 & $12.2-13.9$ & 1.00 & & & & & \\
\hline Female & 471 & 396 & 13.7 & $12.0-15.4$ & 0.88 & $0.78-1.00$ & 0.04 & & & \\
\hline Preop KPS score & - & - & - & - & 0.98 & $0.98-0.99$ & $<0.001$ & & & \\
\hline \multicolumn{11}{|l|}{ Preop KPS score } \\
\hline$\geq 70$ & 1134 & 951 & 13.6 & $12.9-14.3$ & 1.00 & & & 1.00 & & \\
\hline$<70$ & 95 & 84 & 9.9 & $7.6-12.2$ & 1.49 & $1.19-1.86$ & $<0.001$ & 1.30 & $1.04-1.64$ & 0.02 \\
\hline \multicolumn{11}{|l|}{ Tumor functional grade* } \\
\hline 1 & 166 & 125 & 17.8 & $15.7-19.8$ & 1.00 & & & & & \\
\hline 2 & 589 & 509 & 12.7 & $11.6-13.8$ & 1.37 & $1.13-1.67$ & 0.002 & & & \\
\hline 3 & 469 & 396 & 13.2 & $12.2-14.2$ & 1.29 & $1.06-1.58$ & 0.013 & & & \\
\hline \multicolumn{11}{|l|}{ Necrosis on imaging $\dagger$} \\
\hline No & 265 & 195 & 17.8 & $15.4-20.3$ & 1.00 & & & & & \\
\hline Yes & 961 & 837 & 12.7 & $11.9-13.5$ & 1.60 & $1.37-1.88$ & $<0.001$ & & & \\
\hline \multicolumn{11}{|l|}{ Cyst on imaging $\dagger$} \\
\hline No & 1108 & 941 & 13.0 & $12.2-13.7$ & 1.00 & & & 1.00 & & \\
\hline Yes & 118 & 91 & 20.3 & $15.3-25.3$ & 0.60 & $0.48-0.75$ & $<0.001$ & 0.63 & $0.50-0.79$ & $<0.001$ \\
\hline \multicolumn{11}{|l|}{ Symptoms before surgery } \\
\hline No & 105 & 87 & 13.5 & $11.6-15.5$ & 1.00 & & & & & \\
\hline Yes & 1124 & 948 & 13.4 & $12.6-14.2$ & 1.05 & $0.84-1.31$ & 0.65 & & & \\
\hline \multicolumn{11}{|l|}{ Previously treated } \\
\hline No & 752 & 613 & 14.9 & $13.7-16.1$ & 1.00 & & & 1.00 & & \\
\hline Yes & 477 & 422 & 10.8 & $9.9-11.7$ & 1.42 & $1.26-1.62$ & $<0.001$ & 1.67 & $1.46-1.90$ & $<0.001$ \\
\hline Preop T1 contrast-enhancing vol & - & - & - & - & 1.004 & $1.002-1.006$ & $<0.001$ & 1.005 & $1.002-1.007$ & $<0.001$ \\
\hline \multicolumn{11}{|l|}{$\begin{array}{l}\text { EOR of T1 contrast-enhancing } \\
\text { vol }\end{array}$} \\
\hline $100 \%$ & 876 & 722 & 15.2 & $14.1-16.3$ & 1.00 & & & 1.00 & & \\
\hline $78 \%$ to $\leq 100 \%$ & 353 & 313 & 9.8 & $8.8-10.8$ & 1.87 & $1.63-2.14$ & $<0.001$ & 1.53 & $1.33-1.77$ & $<0.001$ \\
\hline
\end{tabular}

* Values based on 1224 patients.

$\dagger$ Values based on 1226 patients.

prior radiation and/or chemo compared with $32 \%$ in those who did not $(p=0.02)$. Figure 3 shows the effect of EOR on survival according to treatment group. A younger age, a higher preoperative KPS score, a cystic tumor, and a smaller preoperative contrast-enhancing tumor on imaging were strong independent positive prognostic factors in this analysis. All categorized continuous variables had a $p$ value $<0.001$. Those $\mathrm{p}$ values remained significant after adjustment for an approximate true false-positive rate of $10 \%$ based on the method of Altman et al. ${ }^{1}$

\section{Postoperative Complications}

A review of postoperative outcomes revealed that $23 \%$ of the 1229 patients included in this study suffered from postoperative complications and $18 \%$ from neurological complications (Table 2). The most common neurological complications were motor deficits $(9 \%)$, followed by speech impairments (6\%) and visual deficits (3\%). Seizures were observed in $2 \%$ of the patients.

The group with less than complete resection had a significantly higher rate of complications than the complete resection group ( $27 \%$ vs $21 \%$, respectively, $\mathrm{p}=0.02)$ and a significantly higher rate of neurological complications ( $22 \%$ vs $17 \%, p=0.02$ ).

In the complete resection group, we compared the overall and neurological postoperative complication rates between patients who also underwent $\geq 53.21 \%$ FLAIR resection with those who had $<53.21 \%$ resection. The rates of overall complications were significantly higher in patients with FLAIR resection < 53.21\% (26\% vs 18\%, p = 0.04; 
TABLE 4. Survival relative to EOR within categories of prognostic variables in 1229 patients with GBM

\begin{tabular}{|c|c|c|c|c|c|c|c|c|c|c|c|}
\hline \multirow[b]{2}{*}{ Variables } & \multicolumn{4}{|c|}{$78 \%$ to $\leq 100 \%$ Resection } & \multicolumn{4}{|c|}{ 100\% Resection } & \multicolumn{3}{|c|}{ Univariate Cox Analysis* } \\
\hline & $\begin{array}{l}\text { Total No. } \\
\text { of Patients }\end{array}$ & $\begin{array}{l}\text { No. of } \\
\text { Events }\end{array}$ & $\begin{array}{c}\text { Median } \\
\text { Survival } \\
\text { (mos) }\end{array}$ & $95 \% \mathrm{Cl}$ & $\begin{array}{l}\text { Total No. } \\
\text { of Patients }\end{array}$ & $\begin{array}{l}\text { No. of } \\
\text { Events }\end{array}$ & $\begin{array}{c}\text { Median } \\
\text { Survival } \\
\text { (mos) }\end{array}$ & $95 \% \mathrm{Cl}$ & $\mathrm{HR}$ & $95 \% \mathrm{Cl}$ & $\mathrm{p}$ Value \\
\hline \multicolumn{12}{|c|}{ Age at surgery in yrs } \\
\hline$\leq 51.7$ & 119 & 100 & 8.9 & $6.8-11.0$ & 337 & 249 & 20.6 & $17.4-23.8$ & 2.47 & $1.94-3.14$ & $<0.001$ \\
\hline$>51.7$ & 234 & 213 & 9.9 & $9.0-10.9$ & 539 & 473 & 13.4 & $12.4-14.3$ & 1.54 & $1.31-1.82$ & $<0.001$ \\
\hline \multicolumn{12}{|l|}{ Sex } \\
\hline Male & 219 & 194 & 9.8 & 8.5-11.2 & 539 & 445 & 14.7 & $13.6-15.7$ & 1.86 & $1.57-2.21$ & $<0.001$ \\
\hline Female & 134 & 119 & 9.7 & $8.3-11.2$ & 337 & 277 & 16.5 & $14.8-18.2$ & 1.86 & $1.50-2.32$ & $<0.001$ \\
\hline \multicolumn{12}{|l|}{ Preop KPS score } \\
\hline$\geq 70$ & 315 & 278 & 10.0 & $8.9-11.1$ & 819 & 673 & 15.5 & $14.5-16.6$ & 1.85 & $1.60-2.13$ & $<0.001$ \\
\hline$<70$ & 38 & 35 & 7.6 & $4.8-10.4$ & 57 & 49 & 13.0 & $8.6-17.5$ & 1.81 & $1.14-2.86$ & 0.01 \\
\hline \multicolumn{12}{|c|}{ Tumor functional grade } \\
\hline 1 & 15 & 14 & 9.3 & $6.3-12.3$ & 151 & 111 & 18.4 & $16.4-20.5$ & 2.41 & $1.37-4.25$ & 0.002 \\
\hline 2 & 180 & 161 & 9.1 & $8.2-10.0$ & 409 & 348 & 14.8 & $13.4-16.1$ & 1.73 & $1.43-2.09$ & $<0.001$ \\
\hline 3 & 156 & 136 & 10.6 & $9.0-12.1$ & 313 & 260 & 14.7 & $13.4-16.0$ & 1.88 & $1.52-2.40$ & $<0.001$ \\
\hline \multicolumn{12}{|l|}{ Necrosis on imaging } \\
\hline No & 40 & 33 & 11.9 & $9.2-14.6$ & 225 & 162 & 19.9 & $17.4-22.3$ & 2.01 & $1.38-2.94$ & $<0.001$ \\
\hline Yes & 313 & 280 & 9.7 & $8.8-10.6$ & 648 & 557 & 14.4 & $13.5-15.4$ & 1.74 & $1.50-2.01$ & $<0.001$ \\
\hline \multicolumn{12}{|l|}{ Cyst on imaging } \\
\hline No & 328 & 295 & 9.6 & $8.7-10.6$ & 780 & 646 & 14.7 & $13.7-15.6$ & 1.80 & $1.56-2.06$ & $<0.001$ \\
\hline Yes & 25 & 18 & 11.5 & $8.6-14.4$ & 93 & 73 & 23.2 & $15.7-30.6$ & 2.36 & $1.37-4.07$ & 0.001 \\
\hline \multicolumn{12}{|c|}{ Symptoms before surgery } \\
\hline No & 20 & 17 & 8.8 & $0.0-17.6$ & 85 & 70 & 14.6 & $11.3-17.8$ & 1.49 & $0.87-2.54$ & 0.15 \\
\hline Yes & 333 & 296 & 9.8 & $8.9-10.7$ & 791 & 652 & 15.4 & $14.2-16.5$ & 1.90 & $1.65-2.18$ & $<0.001$ \\
\hline \multicolumn{12}{|l|}{ Previously treated } \\
\hline No & 213 & 183 & 10.4 & $9.2-11.6$ & 539 & 430 & 17.9 & $16.3-19.6$ & 2.08 & $1.74-2.48$ & $<0.001$ \\
\hline Yes & 140 & 130 & 8.3 & $7.2-9.3$ & 337 & 292 & 12.4 & $11.0-13.8$ & 1.60 & $1.30-1.98$ & $<0.001$ \\
\hline \multicolumn{12}{|c|}{$\begin{array}{l}\text { Preop T1 contrast-en- } \\
\text { hancing vol in } \mathrm{cm}^{3}\end{array}$} \\
\hline$\geq 31.0$ & 244 & 217 & 14.2 & $12.9-15.5$ & 361 & 300 & 11.4 & $10.4-12.4$ & 1.81 & $1.51-2.16$ & $<0.001$ \\
\hline$<31.0$ & 109 & 96 & 16.1 & $14.5-17.7$ & 492 & 400 & 14.6 & $13.3-15.9$ & 1.72 & $1.37-2.16$ & $<0.001$ \\
\hline
\end{tabular}

* $100 \%$ resection is the referent group.

Table 7). The rates of neurological complications were not significantly different between the 2 groups $(\mathrm{p}=0.12)$.

\section{Discussion}

The current standard of care for patients with GBM is resection followed by adjuvant chemoradiotherapy. Several patient and tumor variables have been shown to affect the prognosis of patients with GBM, including age, preoperative functional status, and preoperative imaging characteristics of the tumor. Additionally, the prognostic value of EOR has been repeatedly confirmed, ${ }^{15,19,20}$ and authors of these studies and others have suggested that at least $78 \%-89 \%$ of the contrast-enhancing tumor volume needs to be resected for a significant survival advantage. In the current study, we first explored the influence of complete resection, that is, surgical removal of the entire contrastenhancing region, on patient survival. Complete resection was achieved in 876 patients (71\%). The 15.2-month median survival time among these patients was about 5.4 months longer than the median survival for patients undergoing less than complete resection $(\mathrm{p}<0.001)$, a finding supported by our multivariate analysis (adjusted HR for the less than complete resection group $1.53,95 \% \mathrm{CI}$ $1.33-1.77, \mathrm{p}<0.001)$. The 2 resection groups had significant differences in important characteristics, which could have affected overall survival. We examined the effect of EOR within various categories of these characteristics. The hazard ratio remained basically unaltered in terms of direction, and the $\mathrm{p}$ values remained significant in all categories except for an asymptomatic presentation, alleviating concern that such a finding is attributable to a different distribution of prognostic variables between the 2 resection groups.

Therefore, the conclusion supported by the data and the one that should be emphasized to practicing neurosurgeons is that every attempt should be made to resect the totality of the contrast-enhancing portion of a GBM tumor, 


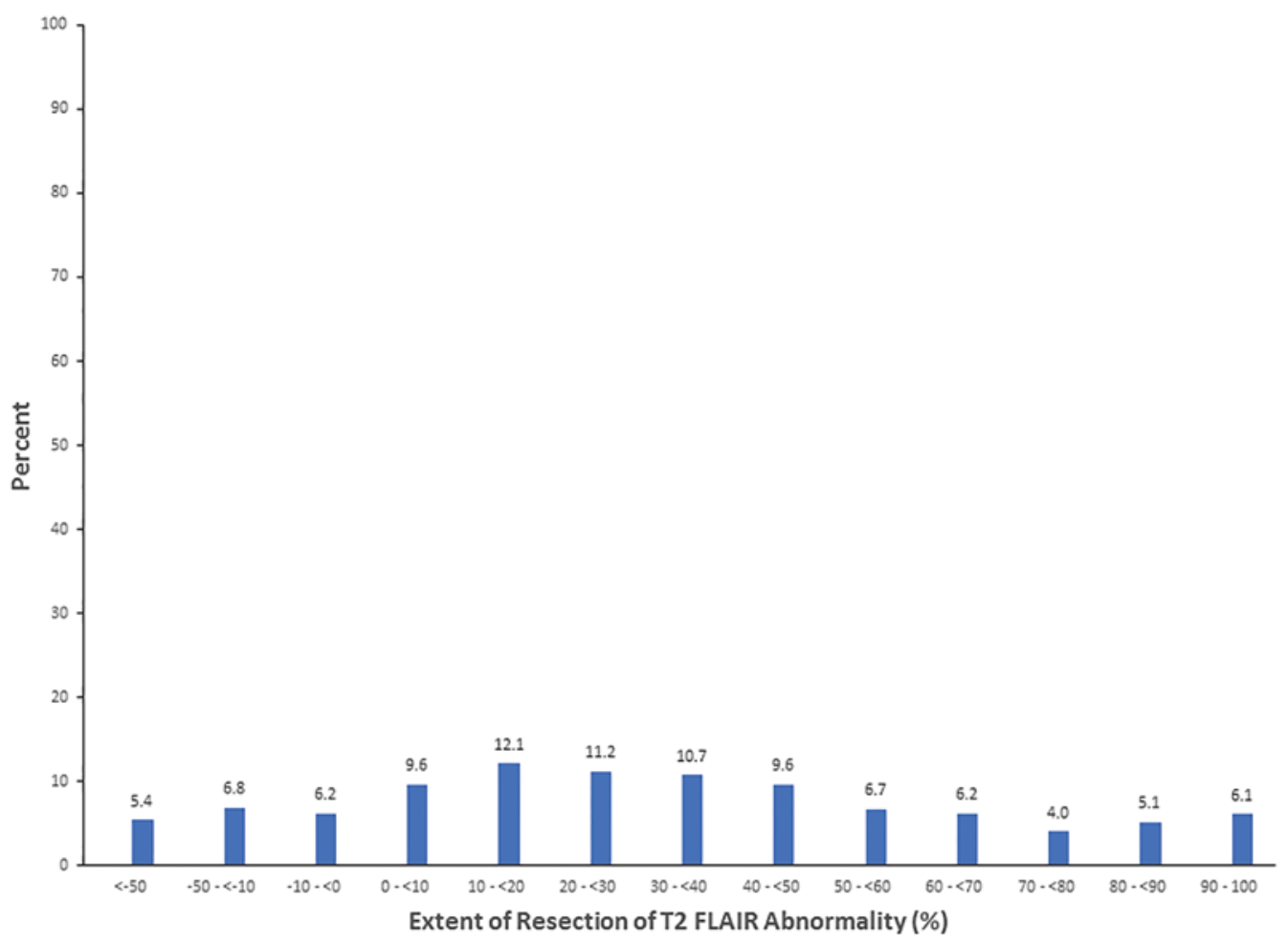

FIG. 2. Histogram showing percentages of 643 patients who underwent different EORs of the T2 FLAIR abnormality region for GBM. Figure is available in color online only.

as this approach will lead to a maximal survival benefit. In addition, given that the contrast-enhancing portion of a tumor is entirely composed of tumor cells, ${ }^{16}$ the goal of complete resection should be achievable in most patients with GBM, even when the lesion is located within or near eloquent brain.

The incidence of complications was not higher in patients who underwent complete resection than in those who underwent less than complete resection. Rather, it was the other way around. This finding probably reflects the sicker status of the latter group, which we corrected for in the multivariate analysis of survival.

As noted previously, the invasiveness of GBM has been demonstrated in vitro, in vivo, and in postmortem and other studies. The majority of patients succumbing to GBM die of local tumor recurrence, presumably from regrowth of infiltrating tumors left behind in the vicinity of the original tumor. Cerebral edema, demyelination, and/ or surgery-related injury represent an important component of the T2 FLAIR abnormality region. ${ }^{9,28}$ In cases in which edema is a significant component after resection of the enhancing mass, the FLAIR signal shrinks considerably. But the tumor component reflecting the invasive nature of GBM cannot be ignored. ${ }^{8,9,13,26,28}$ The area outside the contrast-enhancing region on T1-weighted MRI is usually infiltrated by tumor cells. These appear on T2 FLAIR images, ${ }^{8,13}$ therefore, we explored the effect of additional resection of the T2 FLAIR abnormality region in the subgroup that had undergone complete resection of their contrast-enhancing tumor.

We identified the subset of patients in whom some
FLAIR abnormality region was resected. Of note, only around $30 \%$ of patients in our study had $>50 \%$ resection of the T2 FLAIR abnormality. When these cases were performed, there was no evidence in the literature to support a resected FLAIR region as a significant positive prognostic factor, nor was there evidence on the safety of additional FLAIR resection, hence the apparent reluctance of our surgeons to push the boundary of T2 FLAIR resection. To our knowledge, this study is the first to present data on the effect of T2 FLAIR resection in a large number of patients. The literature does support aggressive resection of the enhancing lesion, a practice rigorously followed at our center, as reflected in our study data on resecting the contrast-enhancing tumor volume. Resecting a portion of the T2 FLAIR abnormality region did confer an added survival benefit over complete resection at the univariate analysis level. The trend remained strong at the multivariate level. Such a benefit was observed in patients undergoing at least $53.21 \%$ resection of the FLAIR abnormality compared with those undergoing a less extensive resection. This advantage of the $\geq 53.21 \%$ EOR group over the $<53.21 \%$ EOR group was initially observed in the univariate analysis in both the previously untreated patient subset (median survival 23.2 months, 95\% CI 17.8-28.6 months compared with 18.7 months, 95\% CI 16.9-20.5 months, respectively) and in the previously treated patient subset (median survival 19.8 months, 95\% CI 15.3-24.3 months compared with 11.2 months, 95\% CI 9.8-12.6 months, respectively). In the multivariate analysis, after correcting for other independent prognostic factors, the previously treated group with $<53.21 \%$ resection had significantly 
TABLE 5. Survival in 643 patients with GBM whose entire T1 contrast-enhancing tumor portion was resected and who had EOR of T2 FLAIR abnormality data*

\begin{tabular}{|c|c|c|c|c|c|c|c|c|c|c|c|}
\hline \multirow[b]{2}{*}{ Variable } & \multirow{2}{*}{$\begin{array}{l}\text { No. of } \\
\text { Patients w/ } \\
\text { Data } \\
\text { Available }\end{array}$} & \multirow{2}{*}{$\begin{array}{l}\text { No. of } \\
\text { Death } \\
\text { Events }\end{array}$} & \multirow{2}{*}{$\begin{array}{l}\text { Median } \\
\text { Survival } \\
\text { (mos) }\end{array}$} & \multirow[b]{2}{*}{$95 \% \mathrm{Cl}$} & \multirow{2}{*}{$\begin{array}{l}\text { p Value } \\
\text { (log- } \\
\text { rank) }\end{array}$} & \multicolumn{3}{|c|}{ Univariate Analysis } & \multicolumn{3}{|c|}{ Multivariate Analysis } \\
\hline & & & & & & HR & $95 \% \mathrm{Cl}$ & $\begin{array}{c}p \\
\text { Value }\end{array}$ & HR & $95 \% \mathrm{Cl}$ & Value \\
\hline Overall survival & $643(100)$ & 502 & 16.8 & $15.4-18.2$ & & & & & & & \\
\hline Age at surgery & - & - & - & - & - & 1.03 & $1.02-1.04$ & $<0.001$ & 1.03 & $1.02-1.04$ & $<0.001$ \\
\hline \multicolumn{12}{|l|}{ Sex } \\
\hline Male & $399(62)$ & 315 & 15.2 & $13.8-16.7$ & & 1.00 & & & & & \\
\hline Female & $244(38)$ & 187 & 18.7 & $16.8-20.5$ & 0.003 & 0.76 & $0.63-0.91$ & 0.004 & & & \\
\hline Preop KPS score & - & - & - & - & - & 0.98 & $0.98-0.99$ & $<0.001$ & 0.988 & $0.981-0.995$ & 0.001 \\
\hline \multicolumn{12}{|l|}{ Preop KPS score } \\
\hline$\geq 70$ & $601(93)$ & 468 & 16.9 & $15.5-18.3$ & & 1.00 & & & & & \\
\hline$<70$ & $42(6)$ & 34 & 14.7 & $9.6-19.9$ & 0.14 & 1.30 & $0.92-1.84$ & 0.14 & & & \\
\hline \multicolumn{12}{|l|}{ Tumor functional grade } \\
\hline 1 & $127(20)$ & 88 & 18.9 & $17.2-20.5$ & & 1.00 & & & & & \\
\hline 2 & $304(47)$ & 249 & 15.5 & $13.9-17.2$ & & 1.29 & $1.01-1.65$ & 0.04 & & & \\
\hline 3 & $212(33)$ & 165 & 16.9 & $13.7-20.1$ & 0.03 & 1.03 & $0.80-1.34$ & 0.81 & & & \\
\hline \multicolumn{12}{|l|}{ Necrosis on imaging } \\
\hline No & $184(29)$ & 129 & 19.9 & $18.0-21.8$ & & 1.00 & & & & & \\
\hline Yes & $459(71)$ & 373 & 15.4 & $14.0-16.7$ & 0.003 & 1.35 & $1.10-1.65$ & 0.004 & & & \\
\hline \multicolumn{12}{|l|}{ Cyst on imaging } \\
\hline No & $575(89)$ & 449 & 15.9 & 14.6-17.2 & & 1.00 & & & & & \\
\hline Yes & $68(10)$ & 53 & 24.5 & $14.5-34.5$ & 0.007 & 0.68 & $0.51-0.90$ & 0.008 & 0.66 & $0.49-0.90$ & 0.009 \\
\hline \multicolumn{12}{|l|}{ Symptoms before surgery } \\
\hline No & $64(10)$ & 50 & 16.9 & 13.9-19.9 & & 1.00 & & & & & \\
\hline Yes & $579(90)$ & 452 & 16.7 & $15.2-18.1$ & 0.96 & 0.99 & $0.74-1.33$ & 0.96 & & & \\
\hline \multicolumn{12}{|l|}{ Previously treated } \\
\hline No & $403(63)$ & 302 & 19.7 & 18.0-21.4 & & 1.00 & & & & & \\
\hline Yes & $240(37)$ & 200 & 12.4 & $10.7-14.0$ & $<0.001$ & 1.69 & $1.41-2.02$ & $<0.001$ & & & \\
\hline $\begin{array}{l}\text { Preop T1 contrast-enhanc- } \\
\text { ing vol }\end{array}$ & - & - & - & - & - & 1.004 & $1.001-1.007$ & 0.02 & 1.004 & $1.001-1.008$ & 0.03 \\
\hline $\begin{array}{l}\text { Preop T2 FLAIR abnormal- } \\
\text { ity vol }\end{array}$ & - & - & - & - & - & 1.000 & 0.999-1.002 & 0.69 & & & \\
\hline \multicolumn{12}{|l|}{$\begin{array}{l}\text { EOR of T2 FLAIR abnor- } \\
\text { mality vol }\end{array}$} \\
\hline$<53.21 \%$ & $484(75)$ & 390 & 15.5 & $14.1-17.0$ & & 1.00 & & & & & \\
\hline$\geq 53.21 \%$ & $159(25)$ & 112 & 20.7 & $18.2-23.1$ & $<0.001$ & 0.68 & $0.55-0.84$ & $<0.001$ & & & \\
\hline \multicolumn{12}{|l|}{$\begin{array}{l}\text { EOR of T2 FLAIR abnor- } \\
\text { mality vol by previous } \\
\text { treatment }\end{array}$} \\
\hline Treated, $<53.21 \%$ & 199 (31) & 166 & 11.2 & $9.8-12.6$ & & 1.00 & & & 1.00 & & \\
\hline $\begin{array}{l}\text { Treated, } \geq 53.21 \% \text { or } \\
\text { not treated, } \\
<53.21 \%\end{array}$ & $327(51)$ & 258 & 18.7 & $17.0-20.4$ & & 0.62 & $0.51-0.75$ & $<0.001$ & 0.49 & $0.40-0.61$ & $<0.001$ \\
\hline Not treated, $\geq 53.21 \%$ & 117 (18) & 78 & 23.0 & $17.6-28.4$ & $<0.001$ & 0.45 & $0.34-0.59$ & $<0.001$ & 0.43 & $0.33-0.57$ & $<0.001$ \\
\hline
\end{tabular}

* Values represent numbers of patients (\%) unless otherwise specified.

shorter survival than the other 3 categories (that is, previously treated patients who underwent FLAIR resection $\geq 53.21 \%$, previously untreated patients who underwent FLAIR resection $<53.21 \%$, and previously untreated patients who underwent FLAIR resection $\geq 53.21 \%$ ). The previously untreated group with $\geq 53.21 \%$ resection had the longest survival. (Of note, patients previously treated with radiation and/or chemotherapy had a significantly less extensive T2 FLAIR abnormality resection than those who had not been previously treated.) Therefore, resec- 
TABLE 6. Survival relative to EOR of T2 FLAIR abnormality in 643 patients with GBM who had the entire contrast-enhancing portion of their tumor resected

\begin{tabular}{ccccc}
\hline EOR of T2 FLAIR Abnormality & Total No. of Patients & Total No. of Events & Median Survival (mos) & $95 \% \mathrm{Cl}$ \\
\hline$<-50 \%$ & 35 & 32 & 15.9 & $11.2-20.1$ \\
\hline$-50 \%$ to $<-10 \%$ & 44 & 37 & 16.2 & $10.1-22.3$ \\
\hline$-10 \%$ to $<0$ & 40 & 37 & 10.5 & $8.0-12.9$ \\
\hline 0 to $<10 \%$ & 62 & 47 & 16.1 & $12.2-20.1$ \\
\hline $10 \%$ to $<20 \%$ & 78 & 61 & 14.6 & $9.3-19.9$ \\
\hline $20 \%$ to $<30 \%$ & 72 & 65 & 14.6 & $12.2-16.9$ \\
\hline $30 \%$ to $<40 \%$ & 69 & 55 & 16.0 & $13.1-18.9$ \\
\hline $40 \%$ to $<50 \%$ & 62 & 41 & 16.2 & $10.7-21.8$ \\
\hline $50 \%$ to $<60 \%$ & 43 & 26 & 26.4 & $9.9-42.8$ \\
\hline $60 \%$ to $<70 \%$ & 40 & 32 & 19.5 & $11.4-27.7$ \\
\hline $70 \%$ to $<80 \%$ & 26 & 19 & 22.5 & $11.4-33.5$ \\
\hline $80 \%$ to $<90 \%$ & 33 & 23 & 20.2 & $16.5-23.9$ \\
\hline $90 \%$ to $100 \%$ & 39 & 27 & $15.7-24.7$ \\
\hline
\end{tabular}

* Negative values indicate that the T2 FLAIR abnormality actually increased after surgery relative to the preoperative value; positive values, that it decreased.

tion of a significant portion of the T2 FLAIR abnormality region, if feasible and safely attempted, could have a beneficial impact on the survival of patients with GBM. We believe these results have significant value. Future reviews at our and other centers will hopefully shed more light on the issue, with confirmatory evidence and a better definition of the thresholds involved. Calls to maximize the EOR raise concerns about associated increases in pa- tient morbidity. ${ }^{22}$ We reviewed the surgical morbidity associated with resection in our series. Complete resection was found to be relatively safe if it was feasible, as was removal of the T2 FLAIR abnormality region outside of the T1 contrast-enhancing GBM region. The decreased risk probably reflects the increased use of intraoperative neurophysiological monitoring; functional cortical, subcortical, and language mapping; awake craniotomy tech-

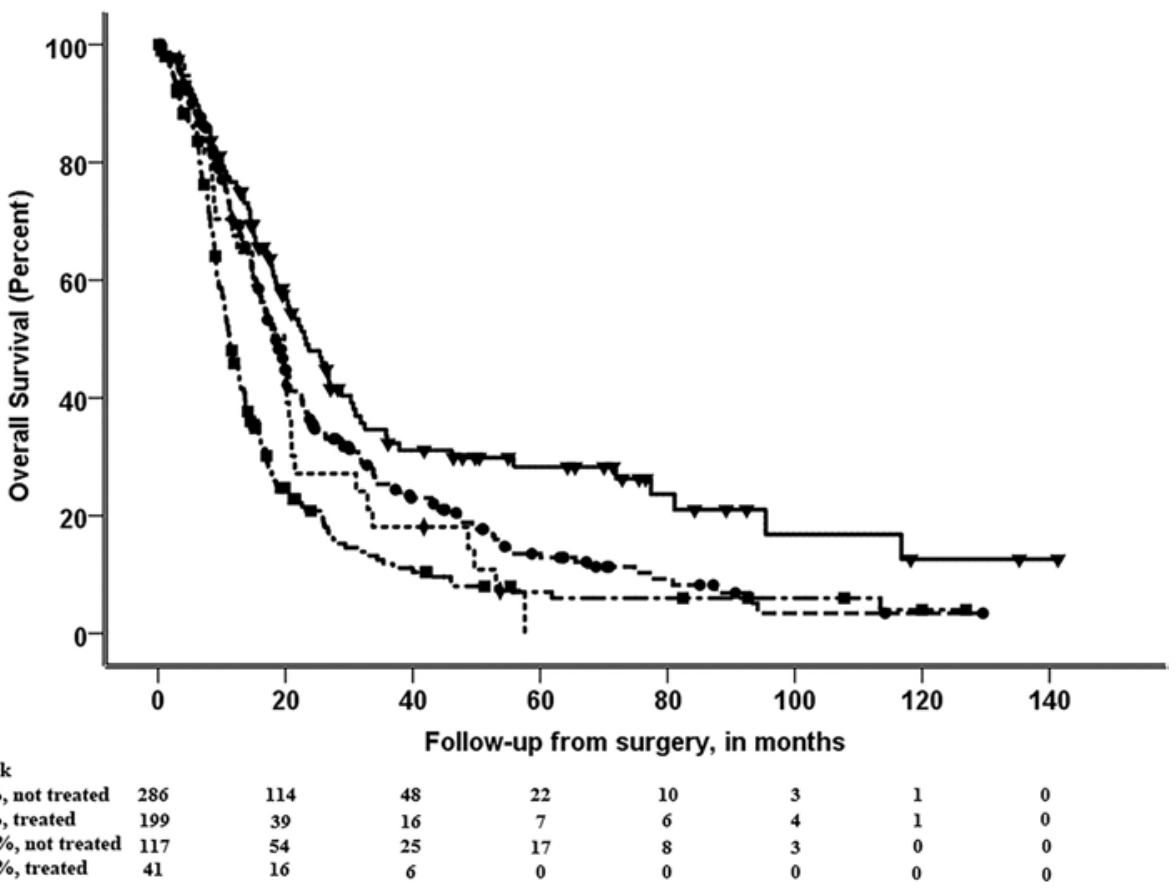

FIG. 3. Kaplan-Meier plot of overall survival in 643 patients with GBM who underwent resection of the T2 FLAIR abnormality region of the tumor after undergoing complete resection, in relation to previous treatment status, either previously treated (treated) or not treated. Represented are patients who underwent $<53.21 \%$ resection, not treated (dashed line; censored, black circles) and treated (dashed-dotted line; censored, black squares); $\geq 53.21 \%$ resection, not treated (solid line; censored, black triangles) and treated (dotted line; censored, black diamonds). 
TABLE 7. Outcomes in 643 patients with GBM treated with additional resection of T2 FLAIR abnormality region*

\begin{tabular}{|c|c|c|c|c|}
\hline Variable & Total No. & $\geq 53.21 \%$ Resection & $<53.21 \%$ Resection & $\mathrm{p}$ Value \\
\hline No. of patients & 643 & 159 & 484 & \\
\hline \multicolumn{5}{|l|}{ 30-day postop complications (\%) } \\
\hline No & $490(76)$ & $131(82)$ & $359(74)$ & \\
\hline Yes & $153(24)$ & $28(18)$ & $125(26)$ & 0.04 \\
\hline \multicolumn{5}{|l|}{ 30-day postop neurological complications (\%) } \\
\hline No & $523(81)$ & $136(86)$ & $387(80)$ & \\
\hline Yes & $120(19)$ & $23(14)$ & $97(20)$ & 0.12 \\
\hline Motor deficit & $57(9)$ & $8(5)$ & $49(10)$ & 0.05 \\
\hline Speech impairment & $46(7)$ & $9(6)$ & $37(8)$ & 0.40 \\
\hline Visual impairment & $18(3)$ & $4(3)$ & $14(3)$ & 1.00 \\
\hline Seizure & $12(2)$ & $1(<1)$ & $11(2)$ & 0.31 \\
\hline Hemorrhage & $11(2)$ & $1(<1)$ & $10(2)$ & 0.31 \\
\hline Intracranial hemorrhage & $9(1)$ & $1(<1)$ & $8(2)$ & 0.46 \\
\hline Hydrocephalus & $7(1)$ & $1(<1)$ & $6(1)$ & 1.00 \\
\hline Cognitive/memory/mental status problems & $8(1)$ & $3(2)$ & $5(1)$ & 0.42 \\
\hline Sensory deficit & $4(<1)$ & $1(<1)$ & $3(<1)$ & 1.00 \\
\hline Headache & $3(<1)$ & $1(<1)$ & $2(<1)$ & 0.57 \\
\hline Cranial nerve deficit & $4(<1)$ & $1(<1)$ & $3(<1)$ & 1.00 \\
\hline Other† & $22(3)$ & $3(2)$ & $19(4)$ & 0.22 \\
\hline
\end{tabular}

nique; neuronavigation overlapping with diffusion tensor imaging (DTI) and functional imaging; and intraoperative MRI. The focus of any GBM resection should be maximal tumor removal while protecting against postoperative neurological or other deficits. If complete $(100 \%)$ resection of the contrast-enhancing tumor is not achievable, then less extensive resections (as dictated primarily by functional mapping) may still provide both symptomatic and survival benefits. Neurosurgeons should aim to perform the maximum resection possible without hurting the patient. Additional resection of the T2 FLAIR region appears to confer an added survival advantage without added risk.

This study has a number of limitations, the main one being that the compared cohorts may be inherently different. There were significant differences in baseline characteristics between patients undergoing $100 \%$ and less than $100 \%$ resection of the contrast-enhancing lesion. A closer examination showed that the findings remained basically unaltered when the effects of EOR on survival were compared within subgroups of these baseline characteristics. In addition to the known differences between the groups being compared, there are probably other inherent differences that are not necessarily easily controlled for within such a study design. In addition, although most of the data were collected prospectively, the study is a retrospective one. As a result, important information was not available to review-for example, the specific reason the neurosurgeon chose to resect the volume that he or she resected-as well as the unavailability of T2 FLAIR MRI studies for some of the earlier patients, which limited the power of the study in some of the subgroup analyses and possibly introduced bias. Despite these limitations, most of the data pointed in the same direction, lending support to the legitimacy of the conclusions derived from this study.

In the absence of better imaging techniques to distinguish between tumor and cerebral edema on FLAIR images, we retrospectively assessed the relation between resection of the FLAIR abnormality area and survival duration and concluded that a greater EOR of the FLAIR area is probably associated with longer patient survival.

\section{Conclusions}

Based on what is, to our knowledge, the largest single-center series of GBM patients with extensive tumor resections, this study supports the established association between EOR and survival. It also provides evidence that the maximum safe resection of contrast-enhancing GBM volume results in a significant survival advantage relative to less extensive resections. Such an outcome is achieved without a significant increase in postoperative neurological deficits or other complications. In addition, in the subgroup that underwent complete resection of the T1 contrast-enhancing region, additional resection of the T2 FLAIR abnormality region may confer a significant added survival advantage. We conclude that pushing the boundary to $100 \%$ resection and beyond, along with the removal of a significant amount of the FLAIR abnormality region, may result in longer survival without significant increases in postoperative morbidity and should be further investigated.

\section{Acknowledgments}

We thank David M. Wildrick, PhD, for editorial assistance and 
Stephanie Jenkins for assistance with manuscript preparation. Data for this work were compiled from a database partly funded by an institutional development grant from The University of Texas MD Anderson Cancer Center.

\section{References}

1. Altman DG, Lausen B, Sauerbrei W, Schumacher M: Dangers of using "optimal" cutpoints in the evaluation of prognostic factors. J Natl Cancer Inst 86:829-835, 1994

2. Bernstein JJ, Goldberg WJ, Laws ER Jr, Conger D, Morreale V, Wood LR: C6 glioma cell invasion and migration of rat brain after neural homografting: ultrastructure. Neurosurgery 26:622-628, 1990

3. Burger PC, Dubois PJ, Schold SC Jr, Smith KR Jr, Odom GL, Crafts DC, et al: Computerized tomographic and pathologic studies of the untreated, quiescent, and recurrent glioblastoma multiforme. J Neurosurg 58:159-169, 1983

4. Burger PC, Heinz ER, Shibata T, Kleihues P: Topographic anatomy and CT correlations in the untreated glioblastoma multiforme. J Neurosurg 68:698-704, 1988

5. Cerame MA, Guthikonda M, Kohli CM: Extraneural metastases in gliosarcoma: a case report and review of the literature. Neurosurgery 17:413-418, 1985

6. Choucair AK, Levin VA, Gutin PH, Davis RL, Silver P, Edwards MS, et al: Development of multiple lesions during radiation therapy and chemotherapy in patients with gliomas. J Neurosurg 65:654-658, 1986

7. Dolecek TA, Propp JM, Stroup NE, Kruchko C: CBTRUS statistical report: primary brain and central nervous system tumors diagnosed in the United States in 2005-2009. Neuro Oncol 14 (Suppl 5):v1-v49, 2012

8. Earnest F IV, Kelly PJ, Scheithauer BW, Kall BA, Cascino TL, Ehman RL, et al: Cerebral astrocytomas: histopathologic correlation of MR and CT contrast enhancement with stereotactic biopsy. Radiology 166:823-827, 1988

9. Ebos JM, Lee CR, Kerbel RS: Tumor and host-mediated pathways of resistance and disease progression in response to antiangiogenic therapy. Clin Cancer Res 15:5020-5025, 2009

10. Greene GM, Hitchon PW, Schelper RL, Yuh W, Dyste GN: Diagnostic yield in CT-guided stereotactic biopsy of gliomas. J Neurosurg 71:494-497, 1989

11. Hochberg FH, Pruitt A: Assumptions in the radiotherapy of glioblastoma. Neurology 30:907-911, 1980

12. Ibayashi N, Herman MM, Boyd JC, Rubinstein LJ: Relationship of invasiveness to proliferating activity and to cytoskeletal protein production in human neuroepithelial tumors maintained in an organ culture system: use of human cortex and dura as supporting matrices. Neurosurgery 26:629-637, 1990

13. Kelly PJ, Daumas-Duport C, Kispert DB, Kall BA, Scheithauer BW, Illig JJ: Imaging-based stereotaxic serial biopsies in untreated intracranial glial neoplasms. J Neurosurg 66:865-874, 1987

14. Kreisl TN: Chemotherapy for malignant gliomas. Semin Radiat Oncol 19:150-154, 2009

15. Lacroix M, Abi-Said D, Fourney DR, Gokaslan ZL, Shi W, DeMonte F, et al: A multivariate analysis of 416 patients with glioblastoma multiforme: prognosis, extent of resection, and survival. J Neurosurg 95:190-198, 2001

16. Lang FF, Sawaya R, Suki D, McCutcheon IE, Hess KR: Glioblastoma resection. J Neurosurg 116:1166-1167, author reply 1167-1168, 2012

17. Leifer D, Moore T, Ukena T, Wilner D, Thor A, HedleyWhyte ET: Multifocal glioblastoma with liver metastases in the absence of surgery. Case report. J Neurosurg 71:772776, 1989

18. Liwnicz BH, Rubinstein LJ: The pathways of extraneural spread in metastasizing gliomas: a report of three cases and critical review of the literature. Hum Pathol 10:453-467, 1979

19. Marko NF, Weil RJ, Schroeder JL, Lang FF, Suki D, Sawaya RE: Extent of resection of glioblastoma revisited: personalized survival modeling facilitates more accurate survival prediction and supports a maximum-safe-resection approach to surgery. J Clin Oncol 32:774-782, 2014

20. Sanai N, Polley MY, McDermott MW, Parsa AT, Berger MS: An extent of resection threshold for newly diagnosed glioblastomas. J Neurosurg 115:3-8, 2011

21. Sawaya R, Hammoud M, Schoppa D, Hess KR, Wu SZ, Shi WM, et al: Neurosurgical outcomes in a modern series of 400 craniotomies for treatment of parenchymal tumors. Neurosurgery 42:1044-1056, 1998

22. Stummer W, Tonn JC, Mehdorn HM, Nestler U, Franz $\mathrm{K}$, Goetz C, et al: Counterbalancing risks and gains from extended resections in malignant glioma surgery: a supplemental analysis from the randomized 5-aminolevulinic acid glioma resection study. Clinical article. J Neurosurg 114:613-623, 2011

23. Van Meir EG, Hadjipanayis CG, Norden AD, Shu HK, Wen PY, Olson JJ: Exciting new advances in neuro-oncology: the avenue to a cure for malignant glioma. CA Cancer J Clin 60:166-193, 2010

24. Vertosick FT Jr, Selker RG: Brain stem and spinal metastases of supratentorial glioblastoma multiforme: a clinical series. Neurosurgery 27:516-522, 1990

25. Wallner KE, Galicich JH, Krol G, Arbit E, Malkin MG: Patterns of failure following treatment for glioblastoma multiforme and anaplastic astrocytoma. Int J Radiat Oncol Biol Phys 16:1405-1409, 1989

26. Wilson CB: Glioblastoma: the past, the present, and the future. Clin Neurosurg 38:32-48, 1992

27. Yung WA, Horten BC, Shapiro WR: Meningeal gliomatosis: a review of 12 cases. Ann Neurol 8:605-608, 1980

28. Zinn PO, Mahajan B, Sathyan P, Singh SK, Majumder S, Jolesz FA, et al: Radiogenomic mapping of edema/cellular invasion MRI-phenotypes in glioblastoma multiforme. PLoS One 6:e25451, 2011 (Erratum in PLoS One 7:10.1371/annotation/b5267cb3-6aa7-47fc-a648-47f30a7cff3e, 2013)

\section{Disclosure}

This work was supported by a generous gift from the Apache Corporation.

\section{Author Contributions}

Conception and design: Sawaya, Li, Suki. Acquisition of data: Sawaya Li, Suki. Analysis and interpretation of data: all authors. Drafting the article: Li, Suki. Critically revising the article: all authors. Reviewed submitted version of manuscript: all authors. Approved the final version of the manuscript on behalf of all authors: Sawaya. Statistical analysis: Suki. Administrative/technical/material support: Sawaya. Study supervision: Sawaya, Suki.

\section{Correspondence}

Raymond Sawaya, Department of Neurosurgery, Unit 442, The University of Texas MD Anderson Cancer Center, 1515 Holcombe Blvd., Houston, Texas 77030.email: rsawaya@ mdanderson.org. 